\title{
Specificity and sensitivity of blood pressure measurements
}

\author{
H. T. WAALER
}

From the Norwegian Research Council for Science and the Humanities, Oslo

SUMMARY Specificity and sensitivity of a biological test describe the ability of the test to exclude false and to include true positives. A method is described for estimating such values for blood pressure measurement. Estimated values are given for various cut-off levels of the diastolic blood pressure. The method indicates that the optimal cut-off level for defining hypertension is found to be at the blood pressure level where the specificity is approaching $100 \%$ and where the sensitivity is about $20 \%$. For example, for males aged 50-59, this is obtained at the diastolic blood pressure level of $105-110 \mathrm{~mm} \mathrm{Hg}$.

Practically all biological tests have a limited sensitivity and specificity, that is, a limited capability to elicit positive response in a truly diseased individual and a limited capability of not giving positive response in a truly non-diseased individual. These concepts are fundamental for a proper application of any biological test. Treatment of false positives may for some diseases and treatments be a heavy burden; for other conditions it may be close to harmless. Non-treatment of false negatives for serious diseases may cause considerable concern. The balance between the seriousness of the disease and the seriousness of the unavoidable side effects is crucial.

Several biological tests for which these properties have been examined are characterised by a relatively unambiguous definition of the disease. Pulmonary tuberculosis is thus clearly defined by bacilli in the sputum. Tuberculin tests, $x$ ray examinations, and bacteriological examinations of sputum specimens are tests for which the sensitivity and specificity have been thoroughly examined.

Whether hypertension is a disease or only a risk factor is debatable, but the fact is that essential hypertension is treated as if it were a disease. This makes a study of the specificity and sensitivity of the measurements essential. Such a study is complicated by the fact that hypertension is not an either-or phenomenon. The definition of hypertension depends upon the threshold value selected for classifying a person as hypertensive. Sensitivity and specificity should therefore be examined at different levels of this threshold, and the optimum threshold should be selected on the basis of such analyses.

The definition of sensitivity and specificity presupposes the recognition of the true positives. For some diseases, tuberculosis for example, a final judgment is possible. In the case of hypertension the true positives can only be indirectly estimated by the excess frequency of complications following the elevated blood pressure. The actual individuals with the 'disease' cannot be identified, but their numbers can be estimated.

The concept of 'true positives' somehow presupposes that there are two groups of hypertensives, those who (predestined) will be hit by complications and those who will not. However, the truth may also be that they all share an increased risk. For the calculations, this distinction is, however, immaterial.

In this paper I have used the excess mortality to define the true positives. The frequency of blood pressure-related complications in the present material is not known, but it has tentatively been simulated to be twice the mortality in order to check the validity of the conclusions.

\section{Materials and methods}

The statistical material is a 10 -year follow-up of mortality of 70000 people (general population) in the city of Bergen, Norway. The number of deaths is about 10000 . The blood pressure of the 70000 people was measured and recorded by standardised methods in $1963^{1}$ under conditions of mass screening. The pressure was measured twice, with an interval of about five minutes, and the last measurement is used in this paper.

The follow-up of mortality was carried out by matching the blood pressure files with the death files in the Central Bureau of Statistics by means of the individual identification number system. The material is neither completely untreated, nor was it subjected to a systematic follow-up, and it is 
supposed to be only moderately affected by treatment, except at the highest pressure levels. Table 1 gives the total population according to diastolic blood pressure at the initial measurement and the 10-year mortality.

For both sexes and all age groups the mortality increased by blood pressure, and this increase starts at a very low level. For extremely low values of blood pressure an increased mortality is also observed. In this paper I have used the minimum level of mortality as a basis and have calculated the excess number of deaths occurring at the various higher levels of blood pressure. The sum of these excess deaths is the estimate of the true positives.

To obtain estimates of sensitivity and specificity, the boxes in the following table must be determined.

\begin{tabular}{l|cc|c} 
& \multicolumn{2}{|c|}{ Test } & Total \\
\hline DISEASE & Pos & Neg & Pos \\
Neg & a & b & $\mathrm{a}+\mathrm{b}(=$ true positive $)$ \\
Total & $\mathrm{a}+\mathrm{c}$ & $\mathrm{d}$ & $\mathrm{c}+\mathrm{d}(=$ true negative $)$ \\
\hline
\end{tabular}

Sensitivity: $\frac{a}{a+b}$

Specificity: $\frac{d}{c+d}$
Calculations presented in this paper are limited, for the sake of simplicity, to the diastolic pressure (5th phase). Similar calculations can, of course, be carried out for the systolic pressure or for any function of the two pressures. These results will be presented elsewhere in a paper on the relative properties of the diastolic and systolic pressure.

\section{Results}

SENSITIVITY AND SPECIFICITY

The procedure is demonstrated in Table 2 for males aged 50-59. The lowest level of mortality is observed for the diastolic blood pressure levels of 50-59 $(0 \cdot 1375)$ and of $60-69 \mathrm{~mm} \mathrm{Hg}(0 \cdot 1398)$. The excess mortality for higher pressure values is estimated as the excess above $0 \cdot 1398$ (column 6). Out of a total number of 888 deaths, 184 were in excess of the expected mortality and could thus be reasonably attributed to 'elevated blood pressure'. The figure 184 is thus an estimate of the true positive cases. Is this a reasonable figure? It is known that cardiovascular diseases are positively correlated with blood pressure. In a general cohort of 50-59-year-old if Norwegian males, the 10-year frequency of deaths due to $I C D$ code number 410 (heart infarction) ${ }^{2}$ is estimated at $4 \cdot 5 \%$, and due to ICD $430-438 \%$

Table 1 Number observed and 10-year mortality by age, sex and diastolic blood pressure, City of Bergen, Norway

\begin{tabular}{|c|c|c|c|c|c|c|c|c|}
\hline \multirow{3}{*}{$\begin{array}{l}\text { Diastolic } \\
\text { blood } \\
\text { pressure } \\
(\mathrm{mm} \mathrm{Hg})\end{array}$} & \multicolumn{8}{|c|}{ Age groups (years) } \\
\hline & \multicolumn{2}{|l|}{$40-49$} & \multicolumn{2}{|l|}{$50-59$} & \multicolumn{2}{|l|}{$60-69$} & \multicolumn{2}{|l|}{$70-79$} \\
\hline & No. observed & Dead & No. observed & Dead & No. observed & Dead & No. observed & Dead \\
\hline & \multicolumn{8}{|c|}{ MALES } \\
\hline $1-49$ & 22 & 3 & 13 & 2 & 25 & 15 & 23 & 13 \\
\hline 50 & 106 & 5 & 80 & 11 & 106 & 39 & 90 & 59 \\
\hline 60 & 735 & 28 & 565 & 79 & 501 & 201 & 310 & 182 \\
\hline 70 & 1740 & 105 & 1458 & 226 & 1197 & 406 & 572 & 348 \\
\hline 80 & 1656 & 104 & 1669 & 275 & 1201 & 450 & 595 & 366 \\
\hline 90 & 693 & 70 & 830 & 171 & 729 & 300 & 357 & 237 \\
\hline 100 & 191 & 18 & 288 & 67 & 296 & 165 & 169 & 122 \\
\hline 110 & 47 & 10 & 91 & 37 & 113 & 72 & 70 & 56 \\
\hline 120 & 10 & 4 & 29 & 16 & 44 & 32 & 29 & 23 \\
\hline$\geqq 130$ & 10 & 4 & 11 & 4 & 20 & 14 & 13 & 10 \\
\hline \multirow[t]{2}{*}{$\mathbf{\Sigma}$} & 5210 & 351 & 5034 & 888 & 4232 & 1694 & 2228 & 1416 \\
\hline & \multicolumn{8}{|c|}{ FEMALES } \\
\hline $1-49$ & 32 & 3 & 25 & 2 & 38 & 10 & 46 & 29 \\
\hline 50 & 180 & 3 & 73 & 8 & 97 & 25 & 79 & 43 \\
\hline 60 & 1119 & 29 & 698 & $\mathbf{3 8}$ & 557 & 105 & 370 & 166 \\
\hline 70 & 2460 & 75 & 1941 & 120 & 1498 & 239 & 753 & 322 \\
\hline 80 & 2007 & 57 & 2431 & 161 & 1957 & 392 & 900 & 424 \\
\hline 90 & 882 & 32 & 1421 & 137 & 1325 & 346 & 715 & 375 \\
\hline 100 & 216 & 14 & 504 & 62 & 629 & 194 & 395 & 230 \\
\hline 110 & 66 & 7 & 166 & 31 & 288 & 97 & 165 & 111 \\
\hline 120 & 18 & 4 & 63 & 19 & 81 & 34 & 48 & 32 \\
\hline$\geqq 130$ & 9 & 3 & 29 & 7 & 39 & 21 & 20 & 17 \\
\hline $\mathbf{\Sigma}$ & 6989 & 227 & 7351 & 585 & 6509 & 1463 & 3491 & 1749 \\
\hline
\end{tabular}




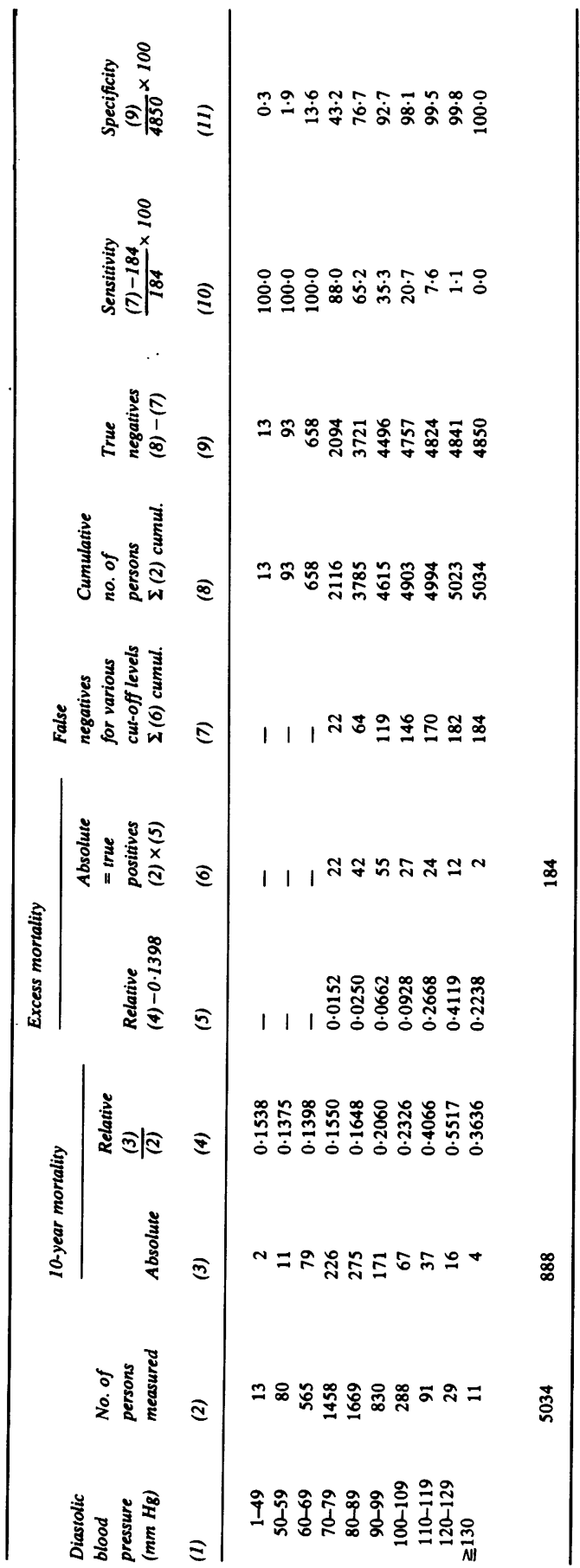

Table 2 Calculations of sensitivity and specificity of blood pressure measurement for males aged 50-59 (cerebrovascular accident) it is $1 \%$, which together are $5 \cdot 5 \%$. In the Bergen material (Table 1) this corresponds to

$$
5034 \cdot 0.055=277
$$

which is $50 \%$ higher that the estimate of 184 . Elevated blood pressure cannot be made responsible for all deaths from these causes. The estimate of 184 true cases therefore seems not unreasonable. They all have a diastolic pressure above $70 \mathrm{~mm} \mathrm{Hg}$. Hence, the sensitivity at this level is $100 \%$. At $80 \mathrm{~mm} \mathrm{Hg}$, the sensitivity is seen to be reduced to $88 \%$ because 22 out of 184 individuals (12\%) will be excluded and defined as (false) negatives. At $130 \mathrm{~mm} \mathrm{Hg}$, the sensitivity is reduced to $1 \cdot 1 \%$.

Up to the level of $70 \mathrm{~mm} \mathrm{Hg}$ all persons will be true negatives (column 9). For higher values, the true negatives are calculated by subtracting the true positives from the total (column 8 minus column 7). The specificity is then calculated at various pressure levels from column 9. For low levels, for instance below $60 \mathrm{~mm} \mathrm{Hg}$, the specificity is very low: $1.9 \%$. Thus, if $60 \mathrm{~mm} \mathrm{Hg}$ and above were defined as hypertension, $(100-1 \cdot 9) \%=98 \cdot 1 \%$ of the treated would be true negatives and therefore over-treated.

Similar calculations for other age groups and for females are summarised in Table 3 and for males aged $50-59$ in Fig. 1 . The pattern varies by age, but hardly by sex. Between 80 and $90 \mathrm{~mm} \mathrm{Hg}$ both sensitivity and specificity will be approximately $70-80 \%$, and at this level their sum will have its maximum.

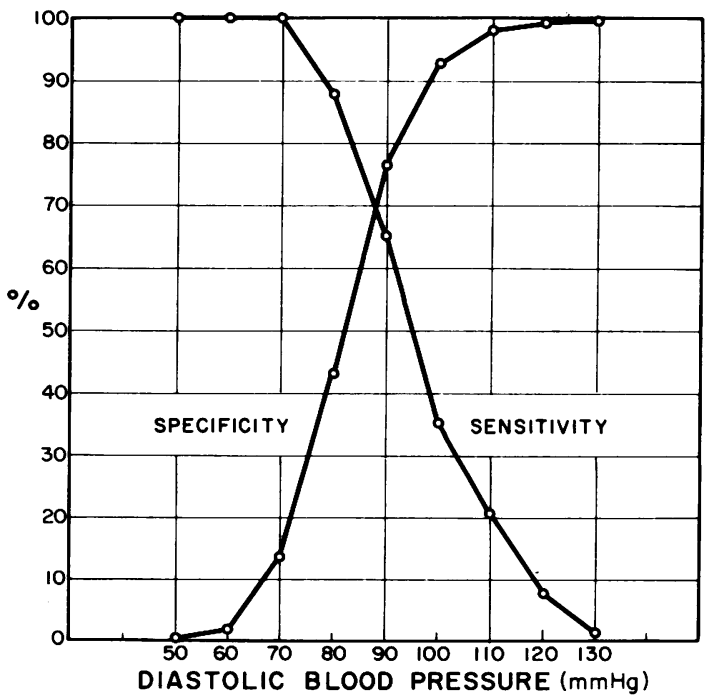

Fig. 1 Sensitivity and specificity of blood pressure measurement by threshold value of the diastolic blood pressure, males aged 50-59. 
Table 3 Sensitivity (fraction of true positives treated) and specificity (fraction of true negatives untreated) by age, sex, and blood pressure threshold

\begin{tabular}{|c|c|c|c|c|c|c|c|c|}
\hline \multirow{3}{*}{$\begin{array}{l}\text { Threshold } \\
\text { diastolic } \\
\text { blood } \\
\text { pressure } \\
(\mathrm{mm} \mathrm{Hg})\end{array}$} & \multicolumn{8}{|c|}{ Age groups (years) } \\
\hline & \multicolumn{2}{|l|}{$40-49$} & \multicolumn{2}{|l|}{$50-59$} & \multicolumn{2}{|l|}{$60-69$} & \multicolumn{2}{|l|}{$70-79$} \\
\hline & Sensitivity & Specificity & Sensitivity & Specificity & Sensitivity & Specificity & Sensitivity & Specificity \\
\hline & \multicolumn{8}{|c|}{ MALES } \\
\hline 50 & $100 \cdot 0$ & 0.4 & $100 \cdot 0$ & $0 \cdot 3$ & $100 \cdot 0$ & 0.6 & $100 \cdot 0$ & $1 \cdot 1$ \\
\hline 60 & $100 \cdot 0$ & $2 \cdot 5$ & $100 \cdot 0$ & $1 \cdot 9$ & $100 \cdot 0$ & $3 \cdot 3$ & $100 \cdot 0$ & $5 \cdot 3$ \\
\hline 70 & $100 \cdot 0$ & $17 \cdot 1$ & $100 \cdot 0$ & $13 \cdot 6$ & $100 \cdot 0$ & $15 \cdot 7$ & $100 \cdot 0$ & 19.9 \\
\hline 80 & $74 \cdot 2$ & $50 \cdot 7$ & $88 \cdot 0$ & $43 \cdot 2$ & $100 \cdot 0$ & $45 \cdot 6$ & $88 \cdot 2$ & $46 \cdot 2$ \\
\hline 90 & $147 \cdot 0$ & $82 \cdot 6$ & $65 \cdot 2$ & $76 \cdot 7$ & $80 \cdot 4$ & $74 \cdot 4$ & $71 \cdot 6$ & 73.4 \\
\hline 100 & $17 \cdot 9$ & 95.4 & $35 \cdot 3$ & $92 \cdot 7$ & $56 \cdot 2$ & $83 \cdot 8$ & $45 \cdot 1$ & 89.0 \\
\hline 110 & $10 \cdot 6$ & 99.0 & $20 \cdot 7$ & $98 \cdot 1$ & $26 \cdot 5$ & $97 \cdot 0$ & $22 \cdot 6$ & $95 \cdot 8$ \\
\hline 120 & $5 \cdot 3$ & 99.8 & $7 \cdot 6$ & $99 \cdot 5$ & $11 \cdot 0$ & $99 \cdot 0$ & $7 \cdot 8$ & $98 \cdot 4$ \\
\hline 130 & 2.7 & 99.9 & $1 \cdot 1$ & 99.8 & $3 \cdot 2$ & 99.7 & $2 \cdot 0$ & $99 \cdot 5$ \\
\hline \multirow[t]{2}{*}{$\geqq 130$} & 0.0 & $100 \cdot 0$ & 0.0 & $100 \cdot 0$ & 0.0 & $100 \cdot 0$ & 0.0 & $100 \cdot 0$ \\
\hline & \multicolumn{8}{|c|}{ FEMALES } \\
\hline 50 & $100 \cdot 0$ & 0.5 & $100 \cdot 0$ & 0.3 & $100 \cdot 0$ & 0.6 & $100 \cdot 0$ & 1.4 \\
\hline 60 & $100 \cdot 0$ & $3 \cdot 1$ & $100 \cdot 0$ & 1.4 & $100 \cdot 0$ & $2 \cdot 2$ & $100 \cdot 0$ & $3 \cdot 8$ \\
\hline 70 & $100 \cdot 0$ & $19 \cdot 2$ & $100 \cdot 0$ & $11 \cdot 1$ & $100 \cdot 0$ & $11 \cdot 3$ & $100 \cdot 0$ & $15 \cdot 2$ \\
\hline 80 & $75 \cdot 6$ & 54.4 & $92 \cdot 3$ & $38 \cdot 0$ & $100 \cdot 0$ & 35.8 & $100 \cdot 0$ & $38 \cdot 3$ \\
\hline 90 & 64.4 & $83 \cdot 3$ & $76 \cdot 2$ & $71 \cdot 5$ & 79.8 & $66 \cdot 5$ & 82.9 & $64 \cdot 6$ \\
\hline 100 & $44 \cdot 4$ & $95 \cdot 8$ & $43 \cdot 1$ & $90 \cdot 5$ & $45 \cdot 7$ & $86 \cdot 0$ & $52 \cdot 6$ & $84 \cdot 4$ \\
\hline 110 & $26 \cdot 7$ & $98 \cdot 8$ & $23 \cdot 8$ & $97 \cdot 0$ & $22 \cdot 0$ & $94 \cdot 8$ & $25 \cdot 9$ & $94 \cdot 8$ \\
\hline 120 & $15 \cdot 6$ & $99 \cdot 7$ & $11 \cdot 6$ & $99 \cdot 0$ & $9 \cdot 1$ & $98 \cdot 6$ & $8 \cdot 3$ & $98 \cdot 5$ \\
\hline 130 & $6 \cdot 7$ & 99.9 & $2 \cdot 8$ & 99.7 & $3 \cdot 8$ & 99.6 & $3 \cdot 5$ & 99.6 \\
\hline$\geq 130$ & 0.0 & $100 \cdot 0$ & $0 \cdot 0$ & $100 \cdot 0$ & 0.0 & $100 \cdot 0$ & 0.0 & $100 \cdot 0$ \\
\hline
\end{tabular}

The results can also instructively be presented by a so-called ROC-curve ${ }^{3}$ as in Fig. 2. The question of trade-off between the two properties becomes essential. Either might be maximised separately, but at the cost of sacrificing the other.

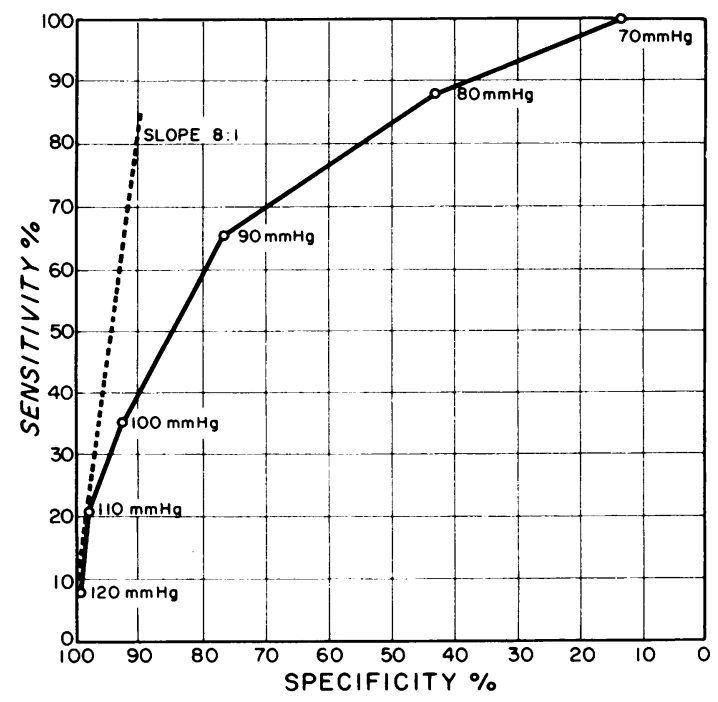

Fig. 2 Receiver operating characteristic curves (ROC). Diastolic blood pressure, males aged 50-59.
OPTIMAL BALANCE BETWEEN SENSITIVITY AN SPECIFICITY

Specificity and sensitivity have to be balanced. Which is the optimal operating position on the ROC-curve? An optimisation process as given by Swets ${ }^{4}$ shows that the optimum occurs where the slope of the ROC-curves equals

where:

$$
\mathrm{s}=A C_{p} \cdot P(D-) / A C_{n} \cdot P(D+)
$$

$\mathrm{AC}_{\mathrm{n}}$ is the additional cost associated with a false negative diagnosis,

$\mathrm{AC}_{\mathrm{p}}$ is the additional cost associated with a false positive diagnosis,

$\mathrm{P}(\mathrm{D}+)$ is the frequency of disease and

$P(D-)=1-P(D+)$ is the frequency of non-disease.

Cost is here defined as the sum of the economically measured resources required and the side effects; it therefore ignores considerations of trade-offs between money and worry.

The slope $s$ and thereby the optimal position on the ROC-curve is determined if the ratio $\mathrm{AC}_{\mathrm{p}} / \mathrm{AC}_{\mathrm{n}}$ and $\mathrm{P}(\mathrm{D}+)$ are known.

If disease is equal to mortality, $\mathrm{P}(\mathrm{D}+)$ for 50-59-year-old males will be (Table 2 ):

$$
184 / 5034=0.0366
$$

and the ratio $\mathrm{P}(\mathrm{D}-) / \mathrm{P}(\mathrm{D}+)=(1-0 \cdot 0366) / 0 \cdot 0366=26 \cdot 3$

Hence the slope (s) will be very steep even if $\mathrm{AC}_{\mathrm{p}}$ is assumed equal to $\mathrm{AC}_{\mathrm{n}}$. The balance between $\mathrm{AC}_{\mathrm{p}}$ and $\mathrm{AC}_{\mathrm{n}}$ is also important. 
Table 4 Estimates ${ }^{5}$ of life years lost according to age, sex, and diastolic blood pressure

\begin{tabular}{|c|c|c|c|c|c|c|c|c|c|c|c|c|}
\hline \multirow{3}{*}{$\begin{array}{l}\text { Age } \\
\text { (years) }\end{array}$} & \multicolumn{12}{|c|}{ Diastolic blood pressure $(\mathrm{mm} \mathbf{H g})$} \\
\hline & \multicolumn{6}{|c|}{ MALES } & \multicolumn{6}{|c|}{ FEMALES } \\
\hline & 85 & 95 & 105 & 115 & 125 & 135 & 85 & 95 & 105 & 115 & 125 & 135 \\
\hline 25 & $2 \cdot 3$ & 4.4 & 7.0 & $10 \cdot 0$ & 13.0 & $15 \cdot 1$ & 3.2 & 6.4 & $10 \cdot 1$ & 13.7 & $17 \cdot 2$ & 20.6 \\
\hline 35 & 1.0 & 2.5 & $4 \cdot 6$ & $7 \cdot 3$ & 10.0 & $12 \cdot 1$ & 1.4 & 3.8 & $7 \cdot 2$ & 10.7 & 14.1 & $17 \cdot 3$ \\
\hline 45 & & 0.9 & 2.5 & 4.7 & $7 \cdot 1$ & $9 \cdot 3$ & 0.5 & 2.0 & 4.7 & 7.9 & $11 \cdot 1$ & $14 \cdot 2$ \\
\hline 55 & & & 0.8 & 2.4 & 4.4 & 6.6 & 0.1 & 0.7 & 2.6 & 5.4 & 8.3 & 10.9 \\
\hline 65 & & & & 0.7 & $2 \cdot 2$ & $4 \cdot 3$ & & & 0.9 & 3.0 & 5.4 & 7.5 \\
\hline 75 & & & & & 0.6 & 1.8 & & & & 0.1 & 2.6 & $4 \cdot 2$ \\
\hline
\end{tabular}

False negative $\left(\mathrm{AC}_{\mathrm{n}}\right)$ means a non-detected true case of hypertension. Non-treatment will presumably increase the probability of reduced survival. Calculations of life years lost have been carried out in our material ${ }^{5}$ and an extract is given in Table 4.

It should be noted, however, that non-detection is not final. A later chance of being detected will occur, depending among other things upon the intensity of the case-finding programme.

False positive $\left(\mathrm{AC}_{\mathrm{p}}\right)$ means a wasted, useless long-term treatment, including the probability of side effects. Often the treatment will be lifelong, with little chance of getting out of the treatment situation.

The simultaneous assessment of $\mathrm{AC}_{\mathrm{p}}$ and $\mathrm{AC}_{\mathrm{n}}$ is a question of clinical judgment, but the immediate impression is that

$$
\mathrm{AC}_{\mathrm{p}} / \mathrm{AC}_{\mathrm{n}}
$$

will be considerably larger than 1: that is, that all costs, as defined above, connected with a false positive is larger than the costs connected with a false negative.

The consequence is that the optimal position on the ROC-curve will be far to the left in the diagram.

\section{Clinical PRACTICE}

Physicians in general practice cannot be expected to take their decisions explicitly according to rules as indicated in this paper. The important question is whether they deviate from the optimal position to any significant extent. Studies of clinical methods in Norway $^{\mathbf{6}} \mathbf{7}$ indicate a great variation in general practice. However, four particularly experienced clinicians, presented with estimates of the potential benefits and the hazards of blood pressure treatment, had no difficulties in reaching an agreement on the threshold above which treatment must be offered. ${ }^{5}$ The value varied by the age of the patient and for patients aged $50-59$ it was $\sim 107 \mathrm{~mm} \mathrm{Hg}$ diastolic pressure on the average. It can be seen from Fig. 2 that this compares with a point on the ROC-curve far to the left and close to the optimal area.

ALTERNATIVE DEFINITION OF 'TRUE POSITIVES' The calculations presented here are limited to estimates of excess mortality. Most complications are, however, non-fatal. Morbidity events should therefore be included. However, we do not have access to similar figures on morbidity in our material. If we assume the total incidence to be, say, twice the mortality, we can simulate the effect of this on the sensitivity and specificity. Table 5 gives the result of this simulation and demonstrates that neither the sensitivity nor the specificity is changed on this basis. Our estimates of the two properties remain unchanged at this low level of incidence.

Table 5 Sensitivity and specificity of blood pressure measurement for males aged 50-59 assuming incidence of events $=2 \times$ mortality

\begin{tabular}{|c|c|c|c|c|}
\hline \multirow{2}{*}{$\begin{array}{l}\text { Threshold } \\
\text { diastolic blood } \\
\text { pressure } \\
\left(\mathrm{mm} \mathrm{Hg}_{\mathrm{g}}\right)\end{array}$} & \multicolumn{2}{|c|}{ Mortality only } & \multicolumn{2}{|c|}{ Simulation of morbidity } \\
\hline & Sensitivity & Specificity & Sensitivity & Specificity \\
\hline 50 & $100 \cdot 0$ & 0.3 & $100 \cdot 0$ & 0.3 \\
\hline 60 & $100 \cdot 0$ & 1.9 & $100 \cdot 0$ & $2 \cdot 0$ \\
\hline 70 & $100 \cdot 0$ & $13 \cdot 6$ & $100 \cdot 0$ & $14 \cdot 1$ \\
\hline 80 & $88 \cdot 0$ & $43 \cdot 2$ & $88 \cdot 0$ & $44 \cdot 4$ \\
\hline 90 & $65 \cdot 2$ & $76 \cdot 7$ & $65 \cdot 2$ & 78.4 \\
\hline 100 & $35 \cdot 3$ & $92 \cdot 7$ & $35 \cdot 1$ & 93.8 \\
\hline 110 & $20 \cdot 7$ & $98 \cdot 1$ & 20.6 & 98.8 \\
\hline 120 & $7 \cdot 6$ & $99 \cdot 5$ & $7 \cdot 1$ & $99 \cdot 7$ \\
\hline 130 & $1 \cdot 1$ & 99.8 & 1.4 & 99.8 \\
\hline$\geqq 130$ & $0 \cdot 0$ & $100 \cdot 0$ & $0 \cdot 0$ & $100 \cdot 0$ \\
\hline
\end{tabular}

The higher prevalence will change the optimal position on the ROC-curve. If 'disease' $=3 \cdot$ mortality, simulating an added morbidity, $\mathrm{P}(\mathrm{D}+)$ will be:

$$
184 \cdot 3 / 5034=0 \cdot 1097
$$

and the ratio $P(D-) / P(D+)=8 \cdot 1$, which also indicates a rather steep slope (see Fig. 2).

\section{Discussion}

Measurement of the blood pressure is a biological test for identifying hypertension. The distribution of blood pressure in a general population is unimodel and does not lend itself readily to selection of the true positives, that is, those who will benefit from treatment. The distribution does not indicate any threshold value for treatment. It is well understood that for lower threshold values (cut-off points), 
over-treatment will be a problem and that for higher values under-treatment will be a problem. The balance between over- and under-treatment is analysed by means of the concepts sensitivity and specificity. Such analysis presupposes knowledge of the true positives and this paper devises a method for estimating this, and thus makes it possible to estimate sensitivity and specificity.

High sensitivity and high specificity is an advantage for biological tests. It is shown in this paper that there is no blood pressure level where both are very high. For males aged 50-59, $85 \mathrm{~mm} \mathrm{Hg}$ diastolic pressure is a point with sensitivity and specificity around $70 \%$; at this level the sum of the two seems to have a maximum. Such a maximum would, however, in the case of blood pressure, never be an optimum. The problem of optimal balance is discussed and it is shown that greater emphasis should be given to the specificity than to the sensitivity. To exclude a true case from treatment, as would be the case with low sensitivity, might only be temporarily, whereas lifelong treatment of a false positive should definitely be avoided, as would be the case with low specificity.

If it is desired to include, say, at least $50 \%$ of the true positives in the defined group of hypertensives, that is, a sensitivity of $50 \%$, one must be content with a specificity of $85 \%$ for males aged $50-59$, that is, an over-treatment of $15 \%$. This will be the case with a threshold value of $95 \mathrm{~mm} \mathrm{Hg}$ diastolic pressure.

If it is found reasonable to cover $70 \%$ of the potential beneficiaries, one is faced with the expected waste of treatment for $30 \%$. The corresponding blood pressure threshold is $90 \mathrm{~mm} \mathrm{Hg}$.

To insist upon a total inclusion (100\% sensitivity) corresponds to an over-treatment of $85 \%$ which will be the case with a threshold value of $70 \mathrm{~mm} \mathrm{Hg}$ diastolic pressure.

The calculations are based upon mortality alone, as the outcome of elevated blood pressure and excess mortality of all causes is used as the definition of true positivity. By simulating a morbidity twice the mortality, it is shown that neither the specificity nor the sensitivity will change.

There is widespread uncertainty in clinical practice about the right cut-off point for defining hypertension. A better understanding of the consequences of varying the threshold, and of the optimisation procedure as given by the concepts of specificity and sensitivity and their mutual trade-offs, might reduce uncertainty.

Reprints from Dr. Hans Th. Waaler, Unit for Health Services Research, the Norwegian Research Council for Science and the Humanities, Fr. Stangsgt 11/13, Oslo 2, Norway.

\section{References}

${ }^{1}$ Eilertsen E, Humerfelt S. The blood pressure in a $\frac{\rho}{\supset}$ representative sample. Acta Med Scand 1968; 4: 293- w 305.

${ }^{2}$ World Health Organisation. International Classification is of Diseases, 8th revision. Geneva: World Healt $\vec{D} \omega$ Organisation, 1967.

${ }^{3}$ McNeil BJ, Keeler E, Addstein SJ. Primer on certai ${ }^{\$}$ elements of medical decision making. $N$ Engl J Med 1975; 293: $1-5$.

${ }^{4}$ Swets JA, ed. Signal Detection and Recognition by humaß observers. New York: Wiley, 1964.

${ }^{5}$ Waaler HT, Helgeland A, Hjort PF, Lund-Johansen P Lund-Larsen P, Mathisen R, Storm-Mathisen H. Hø blodtrykk: behandlingsprogram, utbytte, kostnader.? Oslo: NAVF's gruppe for helsetjenesteforskning, 5/78, 1978.

${ }^{6}$ Fugelli P, Baksaas J, Halvorsen IK, Lunde PKM, Næss K. Høyt blodtrykk i almenpraksis. Oslo: Universitetsforlaget, 1978.

${ }^{7}$ Kvamme J-I, Haider T. Hjerte-karunders $\emptyset$ kelsen $i$ Finnmark. Troms $\varnothing$ : ISM Skriftserie, Universitetsforlaget i Troms $\varnothing$ ) 1978. 